Article

\title{
The Noninvasive Analysis of Paint Mixtures on Canvas Using an EPR MOUSE
}

\author{
Elizabeth A. Bogart ${ }^{+}\left(\mathbb{D}\right.$, , Haley Wiskoski ${ }^{\dagger}$, Matina Chanthavongsay ${ }^{\dagger}$, Akul Gupta ${ }^{\dagger}$ and \\ Joseph P. Hornak * \\ Magnetic Resonance Laboratory, Center for Imaging Science, Rochester Institute of Technology, Rochester, \\ NY 14623, USA; eab3609@rit.edu (E.A.B.); hew3641@rit.edu (H.W.); matina.chanth@gmail.com (M.C.); \\ akulguptax@gmail.com (A.G.) \\ * Correspondence: jphsch@rit.edu; Tel.: +1-585-475-2904 \\ + These authors contributed equally to this work.
}

Received: 6 February 2020; Accepted: 8 March 2020; Published: 12 March 2020

\begin{abstract}
Many artists create the variety of colors in their paintings by mixing a small number of primary pigments. Therefore, analytical techniques for studying paintings must be capable of determining the components of mixtures. Electron paramagnetic resonance (EPR) spectroscopy is one of many techniques that can achieve this, however it is invasive. With the recent introduction of the EPR mobile universal surface explorer (MOUSE), EPR is no longer invasive. The EPR MOUSE and a least squares regression algorithm were used to noninvasively identify pairwise mixtures of seven different paramagnetic pigments in paint on canvas. This capability will help art conservators, historians, and restorers to study paintings with EPR spectroscopy.
\end{abstract}

Keywords: paint mixture analysis; electron paramagnetic resonance spectroscopy (EPR), low frequency electron paramagnetic resonance spectroscopy (LFEPR); EPR mobile universal surface explorer; EPR MOUSE; noninvasive EPR of paintings; unilateral EPR of paintings

\section{Introduction}

Electron paramagnetic resonance (EPR) spectroscopy is one of a vast number of spectroscopic analytical techniques [1-10] used by art conservators, historians, and restorers to study paintings. EPR spectroscopy probes magnetic energy levels associated with unpaired electrons in matter, and is therefore useful for investigating paramagnetic, ferro/ferrimagnetic, and free radical containing pigments. The utility of EPR spectroscopy to the art community has been established. EPR spectroscopy has been used to study rock paintings [11], wall paintings [12], and individual pigments [13-17]. EPR spectroscopy is particularly well suited for studying ancient pigments, as many of these were either transition metal or free radical based. Conventional high frequency EPR (HFEPR) spectrometers operate at $9 \mathrm{GHz}$ and have a limit of detection of $10^{12} \mathrm{spins} / \mathrm{mT}$ of spectral linewidth [18], or $0.3 \mathrm{ppb}$ for a $1 \mathrm{mT}$ linewidth sample. Unfortunately, HFEPR is invasive, limiting the utility of EPR in the study of precious paintings. It is only recently that a low frequency EPR (LFEPR) spectroscopy was developed that made EPR spectroscopy noninvasive for $30 \mathrm{~cm}$ wide paintings $[19,20]$. The more recent development of an EPR mobile universal surface explorer (MOUSE) [21], has made EPR spectroscopy truly noninvasive for all sample size paintings and made the instrument portable for true in situ investigations. The EPR MOUSE performs a contact analysis of a bulk sample, obtaining a signal from a $3 \mathrm{~mm}$ diameter, $1.5 \mathrm{~mm}$ thick disc on the surface.

No single analytical technique alone can determine all possible paint analytes under all possible conditions. Successful studies often rely on complementary techniques [22-26]. Mixtures of paints make the determination of pigments more challenging for any technique. Artists often work with 
a small palette of primary paint colors and mix them to produce the many unique colors in their paintings. For example, Claude Monet had a palette of six primary colors that he mixed to produce the many colors in his masterpieces [27]. Deconvolution of complex spectral line components from mixtures is routinely performed with HFEPR spectroscopy [28-30], but it has never been reported using the surface coil and unilateral magnet combination found in the EPR MOUSE. Demonstrating the ability of the EPR MOUSE to analyze mixtures of pigments in paint on canvas will provide art conservators, historians, and restorers with another noninvasive, complementary analytical technique for studying paintings [31,32]. This study specifically answers the question; can the EPR MOUSE be used to determine the components of a paint mixture spectrum?

\section{Background}

Electron paramagnetic resonance spectroscopy is based on the absorption of photons of energy $E$ and Larmor frequency $v$ by matter with unpaired electrons when placed in an external magnetic field $(B)$. The relationship between $v$ and $B$ is given by Equation (1) and depicted in Figure 1, where $\beta$ and $h$ are physical constants known as the Bohr magneton and Planck's constant, respectively, and the Landé $\mathrm{g}$ factor is an intrinsic constant of matter containing unpaired electrons.

$$
E=\mathrm{h} v=g \beta B
$$

The relationship between $v$ and $B$ is more complex when the atoms have unpaired nuclear spin or multiple unpaired electrons, but Equation (1) will suffice for an understanding of our presentation.

Continuous wave EPR spectra are recorded by sending a fixed $v$ into the sample while scanning $B$. A spectral absorption appears when Equation (1) is satisfied. Spectral absorptions appear as first derivatives of an absorption as a function of $B$ because magnetic field modulation and phase sensitive detection at the modulation frequency are employed to improve the signal-to-noise ratio (SNR) in a spectrum [33].
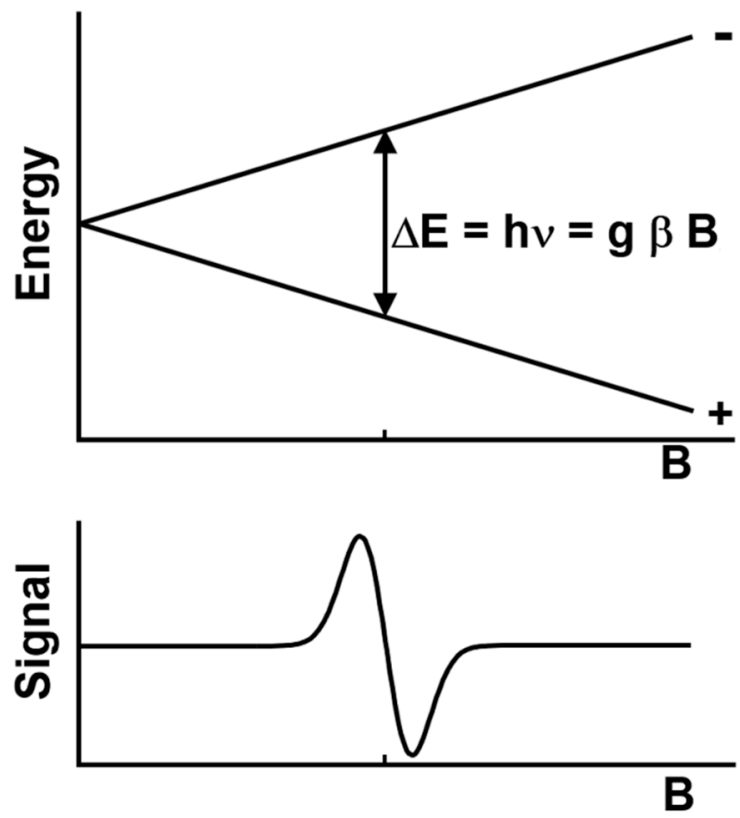

Figure 1. EPR Energy level diagram depicting the relationship between the absorbed energy, first derivative signal, and magnetic field.

The size of the EPR signal is related to the population difference between the two spin levels and given by Boltzmann statistics [33]. The greater the population difference, the larger the signal. 
Defining $N^{-}$and $N^{+}$as the respective number of electron spins in the upper and lower energy levels, $k$ as Boltzmann's constant, and $T$ as the absolute temperature of the sample,

$$
\frac{N^{-}}{N^{+}}=e^{-\left(\frac{h v}{k T}\right)}
$$

HFEPR spectrometers operate at $v=9 \mathrm{GHz}$ and scan $B$ between approximately 100 and $600 \mathrm{mT}$. LFEPR spectrometers generally operate at $v<500 \mathrm{MHz}$ and scan $0<B<50 \mathrm{mT}$. Equation (2) tells us that HFEPR has a larger signal and thus smaller limit of detection than LFEPR.

Continuous wave EPR spectra are recorded by sending a fixed $v$ into the sample while scanning B. A spectral absorption appears when Equation (1) is satisfied. Spectral absorptions appear as first derivatives of an absorption as a function of $B$ because magnetic field modulation and phase sensitive detection at the modulation frequency are employed to improve the SNR in a spectrum [33].

It can be inferred from Equation (2) that the EPR signal is proportional to the number of spins [33]. Lifetime effects and spatial inhomogeneity in $B$ give width to an EPR signal. All other acquisition factors being constant, the number of spins is proportional to the area under an absorption peak. For equal spin concentration samples, the one with the narrowest linewidth will have the lower LOD. EPR spectra of mixtures of equal molar concentrations of two different spin types with different linewidths will retain the relative LOD due to linewidth differences. In pigments, this may be further complicated by the signal being due to an impurity as in Victoria green [34], or a non-stoichiometric free radical as in charcoal [35].

Paramagnetic materials are distinguished from each other by their $\mathrm{g}$ factor, peak-to-peak linewidth $\left(\Gamma_{P P}\right)$, and any splitting pattern from interactions between electron and nuclear spins. The $g$ factor and $\Gamma_{P P}$ are more challenging to quantify with LFEPR because the $\Gamma_{P P}$ is often approximately equal to the sweep width of $B$ and a clear estimation of the signal baseline is not always available to determine the $g$ factor. Additionally, samples with nuclear spin and/or multiple unpaired electrons create spectra that are more challenging to interpret.

The invasive nature of HFEPR spectroscopy and the poorer limit of detection of LFEPR spectroscopy may have hindered the development of EPR for studying paintings. Advances in electronics and the introduction of the EPR MOUSE, which can examine any $3 \mathrm{~mm}$ diameter spherical cap shaped area of an infinite size painting, changes the viability of EPR for studying paintings. Demonstrating the ability of the EPR MOUSE to identify mixtures of two pigments will further advance the viability of EPR spectroscopy for studying paintings.

\section{Materials and Methods}

Seven pigments were chosen to make the paints used in this study: charcoal (C) (Kingsford), Egyptian blue (EB) $\left(\mathrm{CaOCuO}\left(\mathrm{SiO}_{2}\right)_{4}, \mathrm{Kremer}\right.$ Pigments), Han blue $(\mathrm{HB})\left(\mathrm{BaOCuO}\left(\mathrm{SiO}_{2}\right)_{4}, \mathrm{Kremer}\right.$ Pigments), rhodochrosite (RC) ( $\mathrm{MnCO}_{3}$, Kremer Pigments), terracotta red (TCR) (clay flowerpot), ultramarine (UM) $\left(\mathrm{Na}_{8} \mathrm{Al}_{6} \mathrm{Si}_{6} \mathrm{O}_{24} \mathrm{~S}_{3}\right.$, Old Holland), and blue vitriol (BV) (CuSO $4 \cdot 5 \mathrm{H}_{2} \mathrm{O}$, J.T. Baker). Ultramarine and charcoal are respectively sulfur and carbon centered free radicals. Han blue and Egyptian blue are isomorphs, differing only in the presence of barium or calcium ions, and contain paramagnetic $\mathrm{Cu}$ (II) ions. Blue vitriol is also a paramagnetic $\mathrm{Cu}$ (II) ion pigment. Even though these three pigments contain $\mathrm{Cu}$ (II) ions, their EPR properties are very different. Rhodochrosite and terracotta red contain paramagnetic $\mathrm{Mn}(\mathrm{II})$ and Fe(III), respectively. These pigments were selected because they have a known LFEPR signal. [20] The set contains pigments with a variety of $g$ factors, $\Gamma_{P P}$ values, and signal amplitudes, as it is these properties and not colors that matter in EPR spectroscopy analysis. These properties represent the range of possible values and determine the ease of distinguishing between any two pigments in a mixture spectrum.

The pigments were used for seven standard paints. The Ultramarine blue was a premixed, commercial linseed oil-based paint. The Han Blue, Egyptian Blue, and Rhodochrosite powders were used as is, while the blue vitriol, charcoal, and terracotta red were crushed and sieved to have particles 
$<200 \mu \mathrm{m}$. Commercial pigments were confirmed by the manufacturer to be single pigments without additives or secondary pigments added to adjust the color. These pigments were mixed with boiled linseed oil (Houston Art) and mulled in a mortar and pestle to achieve a target pigment volume concentration for each paint of the critical pigment volume concentration based on observed properties of the suspension [36]. The standard paints were then stored in tubes for future use.

The 21 possible pairwise combinations of the seven standard paints were prepared by mixing approximately equal volumes of two standard paints. These mixtures do not have equal mole ratios of the two pigments. Swatches of the seven standard paints and the 21 mixture paints were prepared on titanium dioxide primed canvas. The canvas and primer were determined to have no LFEPR signal. The swatches were heated in an oven at $60^{\circ} \mathrm{C}$ for approximately 24 hours to accelerate the auto-oxidation and subsequent crosslinking of the linseed oil. Each swatch was greater than $7 \mathrm{~mm}$ in diameter and varied in thickness between 1.1 and $2.3 \mathrm{~mm}$. See Figure 2.

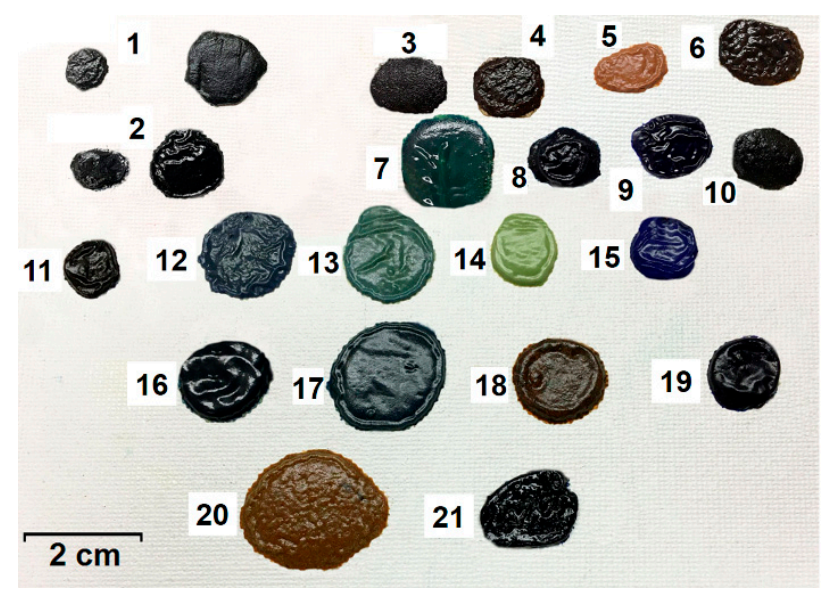

Figure 2. Paint swatches for the 21 pairwise mixtures of pigments. The numbers correspond to 1: RC-C, 2: HB-C, 3:EB-C, 4: TCR-C, 5: RC-TCR, 6: HB-TCR, 7: EB-BV, 8: UM-BV, 9: UM-HB, 10: BV-C, 11: UM-C, 12: RC-HB, 13: EB-RC, 14: BV-RC, 15: RC-UM, 16: HB-EB, 17: HB-BV, 18: EB-TCR, 19: EB-UM, 20: TCR-BV, and 21: TCR-UM.

As EPR spectroscopy with the MOUSE is a bulk analysis, the technique should be capable of determining a paint pigment layer underneath an upper visible one. To test this, one additional swatch was prepared that had a $1.83 \mathrm{~mm}$ base layer of the charcoal paint on canvas, over which a $0.46 \mathrm{~mm}$ layer of ultramarine paint was applied. To prevent diffusion of the pigments between the layers, the charcoal paint was allowed to completely harden before the upper layer of ultramarine was added.

All spectra were acquired on an LFEPR spectrometer and EPR MOUSE described in detail elsewhere $[19,21]$. The EPR MOUSE has a $3 \mathrm{~mm}$ diameter surface coil style sample probe, unilateral magnet, and magnetic field modulation coils, and is connected to the LFEPR spectrometer which provided the B sweep and modulation currents, and the RF bridge for signal detection. Samples were centered on the $3 \mathrm{~mm}$ diameter surface coil of the MOUSE.

The surface coil detects signal from spins in an adjacent spherical cap shaped volume [19]. The further away from the coil, the less the contribution a spin has to the signal. The contribution to the signal from a spin within this volume decreases to $50 \%$ of the surface value at $500 \mu \mathrm{m}$ and $20 \%$ at $1 \mathrm{~mm}$ from the surface [19,21]. Therefore, the signal sensitive region can be thought of as a set of concentric spherical caps with a finite thickness. Each larger cap contributes less per spin to the signal but because the cap volume is becoming larger, the overall contribution increases to a point. The EPR signal (S) from a $3 \mathrm{~mm}$ diameter surface coil as a function of sample thickness $\left(\mathrm{P}_{\mathrm{t}}\right)$ is calculated to be

$$
S \propto\left(1-e^{-k_{c} P_{t}}\right)
$$


where $k_{c}$ is a constant for a given coil. For the MOUSE surface coil $k_{c}=2.65 \mathrm{~mm}^{-1}$, and $S$ reaches $95 \%$ of its maximum value by $1.15 \mathrm{~mm}$. This signal profile drove our use of more impasto-like swatches. The spectral acquisition parameters for all standards and mixtures are summarized in Table 1. All spectra for a swatch were reproducible. All aspects of the spectrometer were controlled by LabVIEW ${ }^{\circledR}$ (National Instruments) code. Spectra were imported into Microsoft Excel for display and analysis.

Table 1. EPR MOUSE spectral acquisition parameters.

\begin{tabular}{cc}
\hline Parameter & Value \\
\hline Spectral Points & 1000 \\
Dwell Time & $215 \mathrm{~ms} / \mathrm{pt}$ \\
Time Constant & $0.3 \mathrm{~s}$ \\
Sweep Start & $0.05 \mathrm{mT}$ \\
Sweep End & $50.48 \mathrm{mT}$ \\
Step Size & $0.05048 \mu \mathrm{T}$ \\
Operating Frequency $(v)$ & $421.8 \mathrm{MHz}$ \\
Modulation Frequency & $10 \mathrm{kHz}$ \\
Modulation Amplitude & $0.22 \mathrm{mT}$ \\
Number of Averages & $4-10$ \\
\hline
\end{tabular}

The analysis of the mixtures consisted of first creating standard spectra $\left(S_{i}(x)\right)$ where $i$ represents the standard number and $x$ the data point in the spectrum for each of the standard swatches. These spectra were a result of averaging at least four individual, $x=1000$ point spectra together to achieve a desirable SNR. Spectra of the mixture swatches $\left(M_{j, k}(x)\right)$ for each of the 21 pairwise mixtures $(j, k)$ of the seven pigments. Additional single mixture spectra were recorded where $j=k$ to check the performance of the algorithm.

The algorithm calculated a trial mixture spectrum $(T(x))$ defined by Equation (4), where $A_{i}$ is the amount of the $i^{\text {th }}$ spectrum contributing to the trial spectrum.

$$
T(x)=\sum_{i}\left(A_{i} S_{i}(x)\right)+S_{o}(x)
$$

$S_{o}(x)$ is a term added to the summation of Equation (4) to account for the possibility of a small linear baseline drift during the acquisition of the mixture spectrum. This term has the form $S_{o}(x)=m x+b$ where $m$ is the slope and $b$ the intercept.

The sum of the square of the residuals between each point of $M_{j, k}(x)$ and $T(x)$ is given by Equation (5).

$$
R=\sum_{x}\left(M_{j, k}(x)-T(x)\right)^{2}
$$

The algorithm determines the combination of $A_{i}, m$, and $b$ necessary to minimize $R$, giving a least squares method. The algorithm was implemented in Microsoft ${ }^{\circledR}$ Office Excel and the $A_{i}$ values determined for each mixture spectrum using the Solver option with the Generalized Reduced Gradient (GRG) nonlinear solving method selected. The Solver was constrained to keep $A_{i} \geq 0$, seeded with $A_{i}=m=b=0$, and terminated with a constraint precision of 0.00001 . Excel was chosen because its availability and widespread use on personal computers. The fraction of each standard paint swatch spectrum in a mixture swatch spectrum was reported as

$$
f_{i}=\frac{A_{i}}{\sum_{i} A_{i}}
$$

To convert $f_{i}$ to a mole fraction, it is necessary to know the molar concentration of each standard paint swatch and either have equal swatch thicknesses or in the case of unequal thicknesses, knowledge of the spatial signal per unit quantity of sample of sensitivity of the MOUSE surface coil. This was not attempted because of the need to know the exact spatial sensitivity of the MOUSE and the challenge of making swatches with equal thickness. 


\section{Results}

The seven standard spectra recorded with the EPR MOUSE are presented in Figure 3, and the $\Gamma_{P P}$ and zero crossing of the spectra are presented in Table 2 . The standards contain spectra with similar and different $\Gamma_{P P}$ and zero crossing, thus providing a good test of the algorithm. The $\Gamma_{P P}$ values are slightly different than those reported by Javier and Hornak [20]. The differences are attributed to the (1) $v=421$ $\mathrm{MHz}$ for the MOUSE and $v=271 \mathrm{MHz}$ for the $2 \mathrm{~cm}$ surface coil, and (2) less homogeneous $B$ of the unilateral magnet on the MOUSE compared to the solenoidal magnet used with the $2 \mathrm{~cm}$ surface coil.
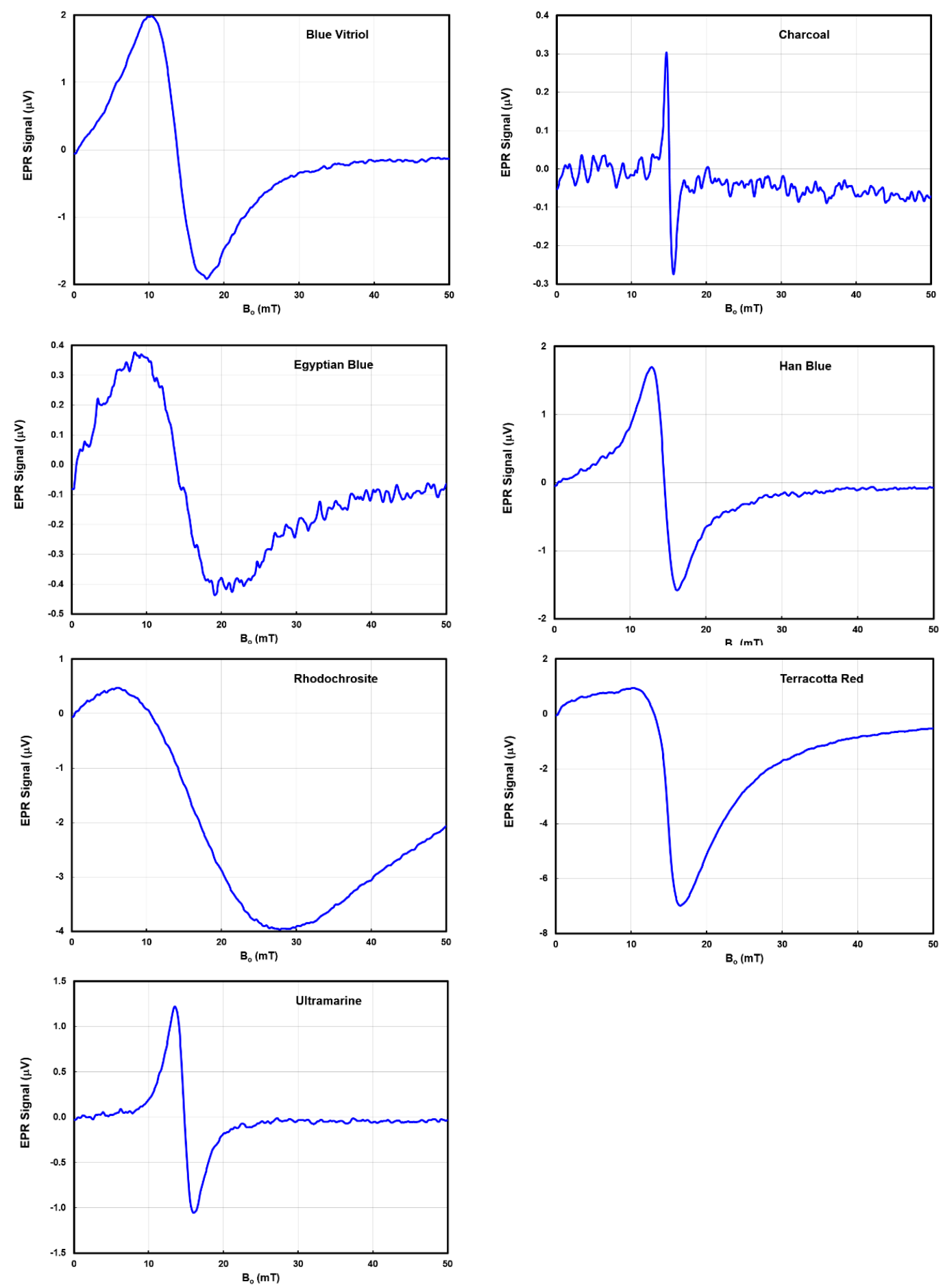

Figure 3. LFEPR spectra of the seven standard paint samples recorded at $421.8 \mathrm{MHz}$ using the EPR MOUSE. 
Table 2. Spectral properties of the seven standard spectra.

\begin{tabular}{ccc}
\hline Pigment & Zero Crossing $(\mathbf{m T})$ & $\boldsymbol{\Gamma}_{\mathbf{P P}}(\mathbf{m T})$ \\
\hline Ultramarine Blue & 14.79 & 2.56 \\
Han Blue & 14.53 & 3.66 \\
Egyptian Blue & 13.96 & 10.85 \\
Terracotta Red & 13.05 & 6.19 \\
Rhodochrosite & 10.48 & 23.63 \\
Charcoal & 15.07 & 0.92 \\
Blue Vitriol & 13.75 & 7.31 \\
\hline
\end{tabular}

These seven spectra were used as the standard spectra in the analysis algorithm. The results from the analysis are separated into two groups. The first is when the mixture spectrum $M_{j, k}$ is composed of a single pigment $(j=k)$. Table 3 summarizes the $f_{i}$ values for each of the seven possible components in the seven $M_{j, k}$ spectra. This group served as a test of the algorithm that was designed to identify multiple components to identify single component spectra.

Table 3. $f_{\mathrm{i}}$ values for the calculated spectral components of single component swatches *.

\begin{tabular}{cccccccc}
\hline & \multicolumn{7}{c}{ Component } \\
\hline Swatch Spectra & C & TCR & HB & EB & RC & UM & BV \\
\hline Charcoal & 0.99 & 0.00 & 0.00 & 0.00 & 0.00 & 0.00 & 0.00 \\
Terracotta Red & 0.00 & 0.99 & 0.00 & 0.00 & 0.00 & 0.00 & 0.01 \\
Han Blue & 0.00 & 0.00 & 1.00 & 0.00 & 0.00 & 0.00 & 0.00 \\
Egyptian Blue & 0.00 & 0.00 & 0.00 & 0.99 & 0.01 & 0.00 & 0.01 \\
Rhodochrosite & 0.00 & 0.00 & 0.00 & 0.04 & 0.96 & 0.00 & 0.00 \\
Ultramarine & 0.01 & 0.00 & 0.00 & 0.00 & 0.00 & 0.99 & 0.00 \\
Blue Vitriol & 0.02 & 0.00 & 0.02 & 0.04 & 0.00 & 0.00 & 0.92 \\
\hline \multicolumn{7}{c}{$* f_{i}$ values rounded to the nearest 0.01.} \\
\hline
\end{tabular}

For this single component $(j=k)$ group, the algorithm identified the correct component by returning a fraction greater than 0.92 in all cases. In five of the cases, the fraction was greater than or equal to 0.99 . In the remaining two cases, rhodochrosite and blue vitriol, the fractions were respectively 0.96 and 0.92 . Since all of these swatches were made from single component paints, the deviation from 1.0 must be attributed to the presence of low frequency spectral noise mimicking the spectra of minor components. To the eye, all spectra fit adequately with $f=1.0$ for the actual component, but minor differences caused by noise cause a better fit with a few percent of other spectra.

The results from the second group of mixture spectrum $M_{j, k}$ occur when $j \neq k$. Table 4 summarizes the $f_{i}$ values for each of the seven possible components in the $21 M_{j, k}$ spectra.

For the 21 swatches in the two-component $j \neq k$ group, the algorithm correctly identified the two primary components in all cases. In six of the 21 mixtures, only the two components were found. In five mixtures, a single extra component was found. In seven mixture spectra, there were two extra minor components; in two mixture spectra, there were three extra minor components; in a single mixture spectrum, there were four extra minor components. The presence of these extra minor components in the fit was again attributed to spectral noise. As with all spectral deconvolution techniques, SNR affects the ability to discriminate between analytes with similar spectral characteristics. The larger the noise and closer its frequency to that of the signal frequency, the more difficult the discrimination between analytes. The two mixtures with the smallest component $\Gamma_{P P}$ difference, UM-HB and TCR-BV, had no minor components identified. There was no correlation with zero crossing similarity and extra components. Both of these observations are characteristic of a random noise process. It should be possible to decrease the noise by using additional signal averaging as well as increasing the time constant and dwell time acquisition parameters, thus increasing the scan time of a spectrum. 
Table 4. $f_{i}$ values for the calculated spectral components of two component swatches *.

\begin{tabular}{cccccccc}
\hline & \multicolumn{7}{c}{ Component } \\
\hline Swatch Spectra & C & TCR & HB & EB & RC & UM & BV \\
\hline Rhodochrosite-Charcoal (1) & 0.68 & 0.00 & 0.00 & 0.00 & 0.32 & 0.00 & 0.00 \\
Han Blue-Charcoal (2) & 0.66 & 0.00 & 0.19 & 0.05 & 0.00 & 0.07 & 0.03 \\
Egyptian Blue-Charcoal (3) & 0.32 & 0.00 & 0.00 & 0.68 & 0.00 & 0.00 & 0.00 \\
Terracotta Red-Charcoal (4) & 0.43 & 0.55 & 0.00 & 0.00 & 0.00 & 0.01 & 0.01 \\
Rhodochrosite-Terracotta Red (5) & 0.00 & 0.61 & 0.00 & 0.00 & 0.38 & 0.00 & 0.01 \\
Han Blue-Terracotta Red (6) & 0.00 & 0.67 & 0.33 & 0.00 & 0.00 & 0.00 & 0.00 \\
Egyptian Blue-Blue Vitriol (7) & 0.00 & 0.00 & 0.00 & 0.70 & 0.02 & 0.00 & 0.28 \\
Ultramarine-Blue Vitriol (8) & 0.00 & 0.00 & 0.00 & 0.27 & 0.05 & 0.03 & 0.65 \\
Ultramarine-Han Blue (9) & 0.00 & 0.00 & 0.60 & 0.00 & 0.00 & 0.40 & 0.00 \\
Blue Vitriol-Charcoal (10) & 0.43 & 0.00 & 0.00 & 0.00 & 0.00 & 0.00 & 0.57 \\
Ultramarine-Charcoal (11) & 0.53 & 0.00 & 0.00 & 0.00 & 0.01 & 0.46 & 0.00 \\
Rhodochrosite-Han Blue (12) & 0.00 & 0.02 & 0.37 & 0.06 & 0.51 & 0.05 & 0.00 \\
Egyptian Blue-Rhodochrosite (13) & 0.00 & 0.01 & 0.00 & 0.40 & 0.58 & 0.00 & 0.01 \\
Blue Vitriol-Rhodochrosite (14) & 0.00 & 0.02 & 0.00 & 0.00 & 0.44 & 0.00 & 0.55 \\
Rhodochrosite-Ultramarine (15) & 0.00 & 0.03 & 0.01 & 0.00 & 0.83 & 0.14 & 0.00 \\
Han Blue-Egyptian Blue (16) & 0.00 & 0.00 & 0.49 & 0.27 & 0.05 & 0.00 & 0.19 \\
Han Blue-Blue Vitriol (17) & 0.00 & 0.00 & 0.29 & 0.00 & 0.03 & 0.04 & 0.64 \\
Egyptian Blue-Terracotta Red (18) & 0.03 & 0.63 & 0.00 & 0.31 & 0.00 & 0.00 & 0.03 \\
Egyptian Blue-Ultramarine (19) & 0.00 & 0.01 & 0.02 & 0.56 & 0.02 & 0.28 & 0.10 \\
Terracotta Red-Blue Vitriol (20) & 0.00 & 0.59 & 0.00 & 0.00 & 0.00 & 0.00 & 0.41 \\
Terracotta Red-Ultramarine (21) & 0.00 & 0.78 & 0.00 & 0.00 & 0.00 & 0.16 & 0.06 \\
\hline
\end{tabular}

${ }^{*} f_{i}$ values rounded to the nearest 0.01 .

Quantitative EPR is challenging [37], and quantitative EPR with a surface coil and unilateral magnet, such as found in the EPR MOUSE, is most challenging process. For this reason, the focus is not on attaining fi $\approx 0.5$ for two component mixtures. Instead, the metric of success is correctly identifying the two components of a mixture having the two largest $f_{i}$ values.

Three examples of the fit to the mixture spectra are presented in Figure 4. These examples were chosen from three general classes of results: (1) only two major $f_{i}$ value, (2) two major and other minor $f_{i}$ values, and (3) two major and one significant minor $f_{i}$ value. The first example is the mixture spectrum for ultramarine and Han blue and the best-fit spectrum consisting of the depicted standard spectra of ultramarine and Han blue. The algorithm found that only the two components were necessary to attain the best fit. Perhaps the need for only two standard spectra is attributed to the slightly larger signal and narrow $\Gamma_{P P}$ values of the components.

The second example is the mixture spectrum for rhodochrosite and ultramarine and the best-fit spectrum consisting of the depicted standard spectra of ultramarine and Han blue. The algorithm found that four components were necessary to attain the best fit: two major components 0.83 rhodochrosite and 0.14 ultramarine, and two minor components 0.03 terracotta red and $0.01 \mathrm{Han}$ blue. The need for the minor components is attributed to the noise level in the spectrum.

The final example is the mixture of Han Blue and Egyptian Blue. The regression algorithm found 0.49 Han blue, 0.27 Egyptian blue, 0.05 rhodochrosite, and 0.19 blue vitriol. The primary components found were the correct ones, but the 0.19 blue vitriol value was unexpectedly large. Perhaps there is some abnormal background baseline drift noise that is best fit with the combination of the wider $\Gamma_{\mathrm{PP}}$ blue vitriol and rhodochrosite contributions. In either event, it is difficult to tell the difference between the best fit with these four components and just Han Blue and Egyptian Blue by using the naked eye. The least squares fit shows that the fit with all four is slightly better. 

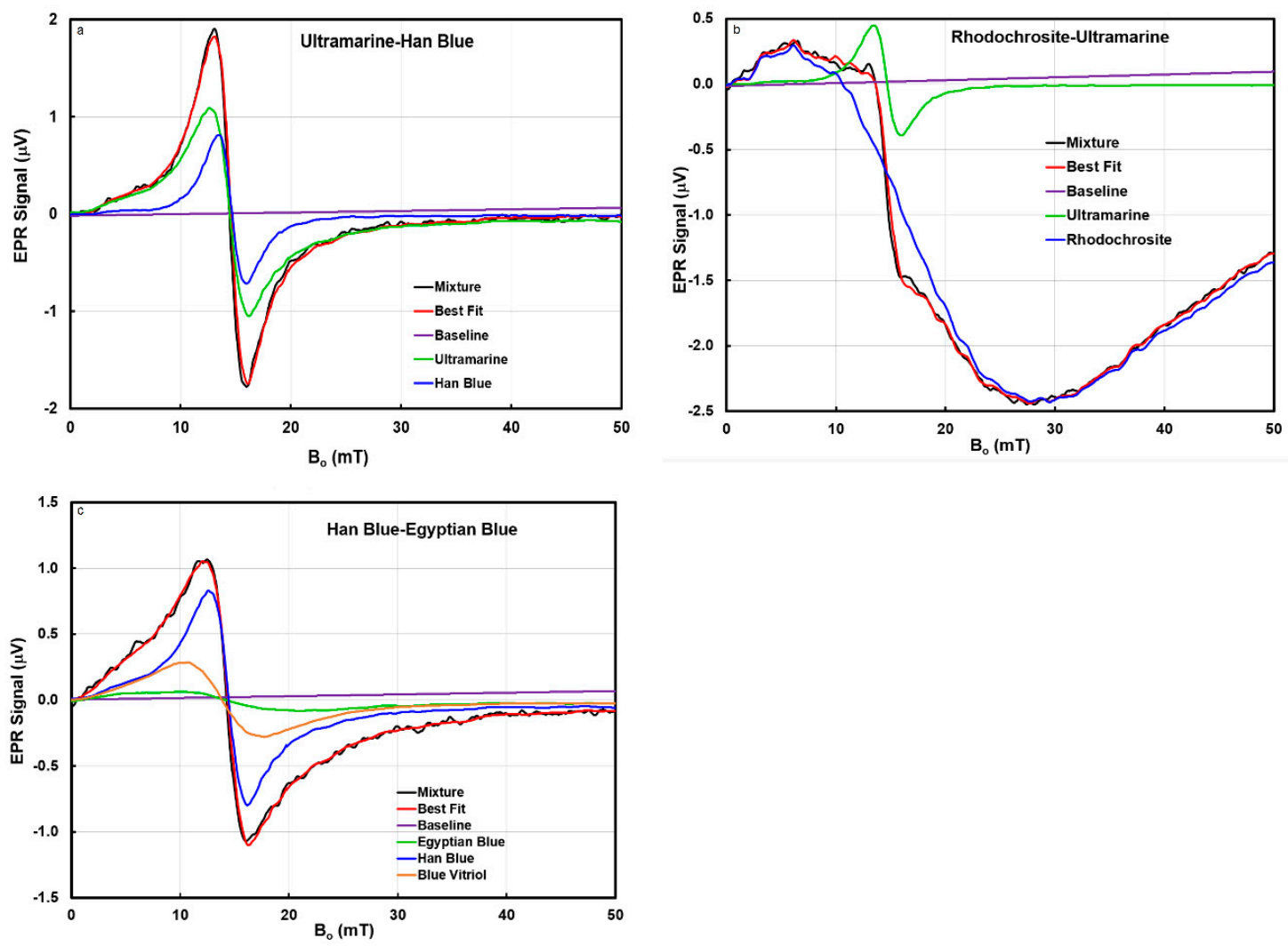

Figure 4. LFEPR analysis spectra of the mixtures (a) ultramarine-Han blue, (b) rhodochrositeultramarine, and (c) Han blue-Egyptian blue. Each plot compares the mixture, best fit, and individual component spectra.

The under-layer results are presented in Table 5. They show that the MOUSE and algorithm were able to identify the two major components: ultramarine and charcoal. Knowing that the swatch was clearly blue, one would conclude that there had to be a charcoal under layer. As with many of the other swatches, it appears as noise in the spectrum caused an erroneous $f_{i}=0.03$ value for terracotta red, which was not present in the sample.

Table 5. $f_{i}$ values for the calculated components of ultramarine over charcoal swatch *.

\begin{tabular}{cccccccc}
\hline & \multicolumn{10}{c}{ Component } \\
\hline Swatch Spectra & C & TCR & HB & EB & RC & UM & BV \\
\hline Ultramarine Over Charcoal & 0.37 & 0.03 & 0.00 & 0.00 & 0.00 & 0.60 & 0.00 \\
\hline & ${ }^{*} f_{i}$ values rounded to the nearest 0.01.
\end{tabular}

The technique will work equally well on these pigments in paintings, provided there is a reasonable SNR and no reactions between or decomposition of the pigments in the mixture [38]. Thicker impasto technique paintings should be easier than thinner paint applications, as there is more pigment in the active volume of the MOUSE surface coil. The technique works well with approximately equal-volume mixtures of pigments. Future studies can determine the limit of detection and spatial sensitivity with more disproportionate mixtures.

\section{Conclusions}

Our results demonstrate that by using the EPR MOUSE and the least-squares regression algorithm, it is possible to identify from a library of seven spectra the correct single or mixture of two pigments that are present in a $3 \mathrm{~mm}$ diameter and up to $1.5 \mathrm{~mm}$ thick region of a painting. Additionally, the 
approach was demonstrated on one under layer, showing that the pigments do not need to be mixed or have a visible surface presence. The MOUSE is nondestructive and because it can look at any sample size, the size of a painting is not an issue and the technique is noninvasive. A single spectrum that is representative of the components in a sample is recorded in as little as four minutes.

The construction cost of the EPR MOUSE and spectrometer was approximately 40,000 USD, or at the lower end of the price of analytical instruments used to study paintings. The analysis does not require purchase of expensive mathematical programming and analysis packages, as the algorithm is implemented in Microsoft ${ }^{\circledR}$ Excel.

Although not explicitly demonstrated, there are two features of the MOUSE worth mentioning. First, it is portable and therefore can examine paintings in situ. Second, it can be used for spectral imaging by rastering the MOUSE across a painting [21,39].

Two negatives of the EPR MOUSE are that it is a contact analysis and its current low SNR. The former cannot be changed, but latter can be improved by signal averaging and improvements to the hardware. Random lower frequency noise may affect the algorithm's ability to discriminate between two pigments with similar $g$ factors and $\Gamma_{P P}$ values.

There is still a need for further technique development work to answer the following questions: Is the technique quantitative such that specific mole fractions of pigments can be determined within a mixture? Will it work equally well on mixtures of three or four pigments? Will it work equally well on a larger set of standard spectra? These questions can best be answered by partnering with art conservators, historians, and restorers. Despite these questions, the analysis works for one or two paramagnetic pigments with an LFEPR signal, so it will complement techniques that are more suitable for organic based pigments.

Author Contributions: Conceptualization, J.P.H.; Data curation, E.A.B., H.W., M.C., A.G. and J.P.H.; Formal analysis, E.A.B., H.W., M.C., A.G. and J.P.H.; Funding acquisition, J.P.H.; Investigation, E.A.B., H.W., M.C., A.G. and J.P.H.; Methodology, J.P.H.; Project administration, J.P.H.; Resources, E.A.B. and J.P.H.; Software, J.H.; Supervision, J.P.H.; Validation, E.A.B., H.W., M.C., A.G. and J.P.H.; Visualization, E.A.B., H.W., M.C., A.G. and J.P.H.; Writing - original draft, J.P.H.; Writing - review \& editing, E.A.B., H.W., M.C. and J.P.H. All authors have read and agreed to the published version of the manuscript.

Funding: This research received no external funding. M. Chanthavongsay acknowledged support from the National Science Foundation REU program under project 1658806.

Conflicts of Interest: The authors declare no conflict of interest.

\section{References}

1. Giorgi, L.; Nevin, A.; Comelli, D.; Frizzi, T.; Alberti, R.; Zendri, E.; Piccolo, M.; Izzo, F. In-situ technical study of modern paintings-Part 2: Imaging and spectroscopic analysis of zinc white in paintings from 1889 to 1940 by Alessandro Milesi (1856-1945). Spectrochim. Acta. A 2019, 219, 504-508. [CrossRef]

2. Rosi, F.; Cartechini, L.; Sali, D.; Miliani, C. Recent trends in the application of Fourier Transform Infrared (FT-IR) spectroscopy in Heritage Science: From micro- to non-invasive FT-IR. Phys. Sci. Rev. 2019, 4. [CrossRef]

3. Brosseau, C.L.; Rayner, K.S.; Casadio, F.; Grzywacz, C.M.; Van Duyne, R.P. Surface-enhanced raman rpectroscopy: A Direct method to identify colorants in various artist media. Anal. Chem. 2009, 81, 7443-7447. [CrossRef]

4. Janssens, K.; Dik, J.; Cotte, M.; Susini, J. Photon-based techniques for nondestructive subsurface analysis of painted cultural heritage artifacts. Acc. Chem. Res. 2010, 43, 814-825. [CrossRef]

5. Calligaro, T.; Gonzalez, V.; Pichon, L. PIXE analysis of historical paintings: Is the gain worth the risk? Nucl. Instrum. Methods B 2015, 363, 135-143. [CrossRef]

6. Cotter, M.J. Neutron Activation Analysis of Paintings: Autoradiography following neutron irradiation provides information for authentication and restoration and reveals the existence of underpaintings undetected by other means. Am. Sci. 1981, 69, 17-27.

7. Lehmann, R.; Wengerowsky, D.J.; Schmidt, H.J.; Kumar, M.; Niebur, A.; Costa, B.F.O.; Dencker, F.; Klingelhöfer, G.; Sindelar, R.; Renz, F. Klimt artwork: Red-pigment material investigation by backscattering Fe-57 Mössbauer spectroscopy, SEM and p-XRF. STAR 2017, 3, 450-455. [CrossRef] 
8. De Meyer, S.; Vanmeert, F.; Vertongen, R.; Van Loon, A.; Gonzalez, V.; Delaney, J.; Dooley, K.; Dik, J.; Van der Snickt, G.; Vandivere, A.; et al. Macroscopic x-ray powder diffraction imaging reveals Vermeer's discriminating use of lead white pigments in Girl with a Pearl Earring. Sci. Adv. 2019, 5, 1971-1979. [CrossRef]

9. Prati, S.; Fuentes, D.; Sciutto, G.; Mazzeo, R. The use of laser photolysis-GC-MS for the analysis of paint cross sections. JAAP 2014, 105, 327-334.

10. Presciutti, F.; Perlo, J.; Casanova, F.; Glöggler, S.; Miliani, C.; Blümich, B.; Brunetti, B.G.; Sgamellotti, A. Noninvasive nuclear magnetic resonance profiling of painting layers. Appl. Phys. Lett. 2008, 93, 033505. [CrossRef]

11. Rowe, M.W. Dating of rock paintings in the Americas: A word of caution. In Pleistocene Art of the World; Clottes, J., Ed.; Société Préhistorique Ariège-Pyrénées: Tarascon-sur-Ariège, France, 2012; Volume 60-61, pp. 573-584.

12. Moretto, L.M.; Orsega, E.F.; Mazzocchin, G.A. Spectroscopic methods for the analysis of celadonite and glauconite in Roman green wall paintings. J. Cult. Herit. 2011, 12, 384-391. [CrossRef]

13. Christiansen, M.B.; Sørensen, M.A.; Sanyova, J.; Bendix, J.; Simonsen, K.P. Characterisation of the rare cadmium chromate pigment in a 19th century tube colour by Raman, FTIR, X-ray and EPR. Spectrochim. Acta Part A Mol. Biomol. Spectrosc. 2017, 175, 208-214. [CrossRef]

14. Gobeltz, N.; Demortier, A.; Lelieur, J.P.; Duhayon, C. Correlation between EPR, Raman and colorimetric characteristics of the blue ultramarine pigments. J. Chem. Soc. Faraday Trans. 1998, 94, 677-681. [CrossRef]

15. Orsega, E.F.; Agnoli, F.; Mazzocchin, G.A. An EPR study on ancient and newly synthesised Egyptian blue. Talanta 2006, 68, 831-835. [CrossRef]

16. Raulin, K.; Gobeltz, N.; Vezin, H.; Touati, N.; Lede, B.; Moissette, A. Identification of the EPR signal of $\mathrm{S}_{2}{ }^{-}$in green ultramarine pigments. Phys. Chem. Chem. Phys. 2011, 13, 9253-9259. [CrossRef]

17. Lakshmi Reddy, S.; Udayabashakar Reddy, G.; Ravindra Reddy, T.; Thomas, A.R.; Rama Subba Reddy, R.; Frost, R.L.; Endo, T. XRD, TEM, EPR, IR and Nonlinear Optical Studies of Yellow Ochre. J. Laser Opt. Photonics 2015, 2, 120. [CrossRef]

18. Wertz, J.E.; Bolton, J.R. Electron Spin Resonance; Chapman and Hall: London, UK, 1986; p. 497.

19. Switala, L.E.; Ryan, W.J.; Hoffman, M.; Javier Santana, S.; Black, B.E.; Hornak, J.P. A Wide-Line Low Frequency Electron Paramagnetic Resonance Spectrometer. Concepts Magn. Reson. 2017, 47B, e21355. [CrossRef]

20. Javier, S.; Hornak, J.P. A Non-Destructive Method of Identifying Pigments on Canvas Using Electron Paramagnetic Resonance Spectroscopy. JAIC 2018, 57, 73-82.

21. Switala, L.E.; Black, B.E.; Mercovich, C.A.; Seshadri, A.; Hornak, J.P. An Electron Paramagnetic Resonance Mobile Universal Surface Explorer. J. Magn. Reson. 2017, 285, 18-25. [CrossRef]

22. Zoleo, A.; Nodari, L.; Rampazzo, M.; Piccinelli, F.; Russo, U.; Federici, C.; Brustolon, M. Characterization of pigment and binder in badly conserved illuminations of a 15th-century manuscript. Archaeometry 2014, 56, 496-512. [CrossRef]

23. Monico, L.; Janssens, K.; Cotte, M.; Sorace, L.; Vanmeert, F.; Brunetti, B.G.; Miliani, C. Chromium speciation methods and infrared spectroscopy for studying the chemical reactivity of lead chromate-based pigments in oil medium. Microchem. J. 2016, 124, 272-282. [CrossRef]

24. Marinescu, M.; Emandi, A.; Duliu, O.G.; Stanculescu, I.; Bercu, V.; Emandi, I. FT-IR, EPR and SEM-EDAX investigation of some accelerated aged painting binders. Vib. Spectrosc. 2014, 73, 37-44. [CrossRef]

25. Vandivere, A.; Wadum, J.; van den Berg, K.J.; van Loon1, A.; The Girl in the Spotlight research team. From 'Vermeer Illuminated' to 'The Girl in the Spotlight': Approaches and methodologies for the scientific (re-) examination of Vermeer's Girl with a Pearl Earring. Herit. Sci. 2019, 7, 1-14. [CrossRef]

26. Anselmi, C.; Vagnini, M.; Cartechini, L.; Grazia, C.; Vivani, R.; Romani, A.; Rosi, F.; Sgamellotti, A.; Miliani, C. Molecular and structural characterization of some violet phosphate pigments for their non-invasive identification in modern paintings. Spectrochim. Acta A. 2017, 173, 439-444. [CrossRef] [PubMed]

27. Kendall, R. Monet by Himself; Kendall, R., Ed.; Cartwell Books, Inc.: Edison, NJ, USA, 2000; p. 327.

28. Flores-Llamas, H.; Ye-Madeira, H. The deconvolution and evaluation of the area under ESR lines. J. Phys. D Appl. Phys. 1992, 25, 970-973. [CrossRef]

29. Magon, C.J.; Lima, J.F.; Donoso, J.P.; Lavayen, V.; Benavente, E.; Navas, D.; Gonzalez, G. Deconvolution of the EPR spectra of vanadium oxide nanotubes. J. Magn. Reson. 2012, 222, 26-33. [CrossRef] [PubMed] 
30. Słowik, G.P.; Więckowski, A.B. Determination of the fraction of paramagnetic centers not-fulfilling. The Curie law in coal macerals by the two-temperature EPR. measurement method. Nukleonika 2015, 60, 389-393. [CrossRef]

31. Chabbra, S.; Smith, D.M.; Bode, B.E. Isolation of EPR spectra and estimation of spin-states in two component mixtures of paramagnetics. Dalton Trans. 2018, 47, 10473. [CrossRef]

32. Ren, J.Y.; Chang, C.Q.; Fung, P.C.; Shen, J.G.; Chan, F.H. Free radical EPR spectroscopy analysis using blind source separation. J. Magn. Reson. 2004, 166, 82-91. [CrossRef]

33. Poole, C.P., Jr. Electron. Spin Resonance, 2nd ed.; John Wiley \& Sons: New York, NY, USA, 1983; p. 780.

34. Navas, A.S.; Reddya, B.J.; Nieto, F. Spectroscopic study of chromium, iron, OH, fluid and mineral inclusions in uvarovite and fuchsite. Spectrochim. Acta Part A 2004, 60, 2261-2268. [CrossRef]

35. Viana, G.A.; Lacerda, R.G.; Freire, F.L.; Marques, F.C. ESR Investigation of Graphite-Like Amorphous Carbon Films Revealing Itinerant States as the Ones Responsible for the Signal. J. Non Cryst. Solids 2008, 354, 2135-2137. [CrossRef]

36. Asbeck, W.K.; Van Loo, M. Critical Pigment Volume Relationships. Ind. Eng. Chem. 1947, 41, 1470-1475. [CrossRef]

37. Eaton, G.R.; Eaton, S.S.; Barr, D.P.; Weber, R.T. Quantitative EPR.; Springer: Berlin/Heidelberg, Germany, 2010; p. 185.

38. Alter, M.; Binet, L.; Touati, N.; Lubin-Germain, N.; Hô, A.-S.L.; François Mirambet, F.; Didier Gourier, D. Photochemical Origin of the Darkening of Copper Acetate and Resinate Pigments in Historical Paintings. Inorg. Chem. 2019, 58, 13115-13128. [CrossRef] [PubMed]

39. Switala, L.E.; Ryan, W.J.; Hoffman, M.; Brown, W.; Hornak, J.P. Low Frequency EPR and EMR Point Spectroscopy and Imaging of a Surface. Magn. Reson. Imaging 2016, 34, 469-472. [CrossRef] [PubMed]

(C) 2020 by the authors. Licensee MDPI, Basel, Switzerland. This article is an open access article distributed under the terms and conditions of the Creative Commons Attribution (CC BY) license (http://creativecommons.org/licenses/by/4.0/). 